\title{
A investigação sobre os modelos de ensino dos jogos desportivos
}

\author{
Amândio Graça \\ Isabel Mesquita
}

https://doi.org/10.5628/rpcd.07.03.401
Faculdade de D esporto

Universidade do Porto

Portugal

\section{RESUMO}

O objectivo deste artigo é o de fazer uma revisão da literatura relativa aos dois modelos mais marcantes na actualidade no que respeita ao ensino dos jogos desportivos, o Teaching Games for Understanding e o Sport Education M odel, considerando os contributos percebidos como mais significativos no que diz respeito à origem dos modelos; às reflexões teórica e apreciações críticas dos modelos, às propostas de revisão e tendências de evolução dos modelos, à literatura de carácter didáctico associada aos modelos; à evolução da investigação empírica directamente associada aos modelos; e, finalmente ao diálogo entre os modelos e os desafios colocados por novas abordagens ao ensino dos jogos desportivos.

Palavras-chave: modelos de ensino, jogos desportivos, TGfU, modelo de educação desportiva

\section{ABSTRACT \\ Research on models for teaching games}

The main goal of this paper is to review the literature related to the Teaching Games for Understanding (TGfU) and the Sport

Education Model (SE), which are presently the most influential models addressing the teaching of sport games. The scope of the review comprehends the contributions perceived to be relevant for examining the roots of the models; the theoretical essays and critical appraisals of the models; the proposals of revision and evolution trends for the models; the didactical literature associated to the models; the evolution of the empirical research directly focused on the models; and finally, the dialogue between the models and the challenges coming from new approaches to the teaching of games.

Key-words: teaching models; team sports, games, TGfU, sport education model 
O ENSINO DOS J OGOS PARA A COMPREENSÃO

A criação e difusão do modelo

O modelo de ensino dos jogos para a compreensão

(Teaching Games for Understanding - TGfU) tem as suas raízes num movimento reformador do ensino dos jogos iniciado nos fins dos anos 60 e anos 70 do século passado, na universidade inglesa de Loughborough(178). Bunker e Thorpe ${ }^{(18)}$, num pequeno artigo intitulado "A Model for the teaching of games in secondary schools", publicado num número do Bulletin of Physical Education, inteiramente dedicado ao tema "Reflecting on the teaching of games" formalizaram, por assim dizer, o aparecimento deste modelo de ensino. No essencial, os proponentes pretendiam que a atenção tradicional mente dedicada ao desenvolvimento das habilidades básicas do jogo, ao ensino das técnicas isoladas, fosse deslocada para o desenvolvimento da capacidade de jogo através da compreensão táctica do jogo. A ideia era deixar de ver o jogo como um momento de aplicação de técnicas, para passar a vê-lo como um espaço de resolução de problemas. Esta ideia é concretizada através do arranjo de formas de jogo apropriadas ao nível de compreensão e de capacidade de intervenção dos alunos no jogo. A adaptação destas formas de jogo fazse por referência a quatro princípios pedagógicos ${ }^{(71,}$ 168, 169): a selecção do tipo de jogo (game sampling); a modificação do jogo por representação (formas de jogo reduzidas representativas das formas adultas de jogo); a modificação por exagero (manipulação das regras de jogo, do espaço e do tempo de modo a canalizar a atenção dos jogadores para o confronto com determinados problemas tácticos); o ajustamento da complexidade táctica (o repertório motor que os alunos já possuem deve permitir-Ihes enfrentar os problemas tácticos ao nível mais adequado para desafiar a sua capacidade de compreender e actuar no jogo). O jogo, objectivado numa forma modificada concreta, é a referência central para processo de aprendizagem, é ele que dá coerência a tudo quanto se faz de produtivo na aula. A centralidade do jogo para este modelo é enfatizada por Waring e Almond(177), quando propõem uma designação alternativa para este modelo -"game-centred games". No ambiente desta forma adaptada de jogo (ver Figura 1), o foco didáctico incidiria sucessiva e ciclicamente sobre a apreciação dos aspectos constituin- tes do jogo; sobre a tomada de consciência dos princípios tácticos do jogo; sobre a tomada de decisão do que fazer e como fazer nas diferentes situações de jogo; sobre a exercitação das habilidades necessárias à melhoria da performance no jogo; e, finalmente, sobre a integração dos aspectos técnicos e tácticos necessários à melhoria da performance no jogo.

\section{MODELO PARA O ENSINO DOS JOGOS DESPORTIVOS}

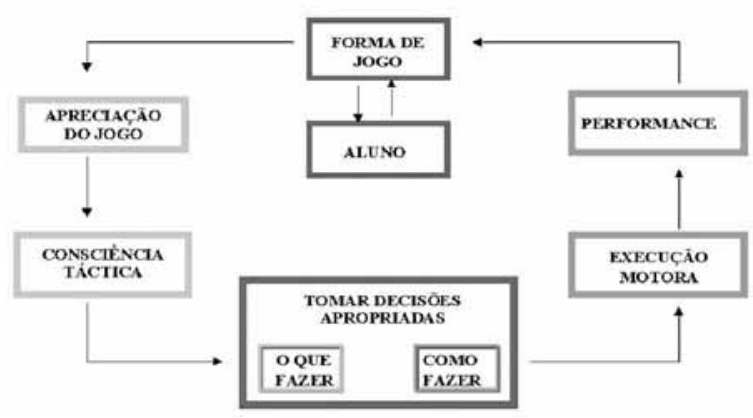

Figura 1. Modelo de ensino dos jogos para a compreensão (TGfU, Bunker e Thorpe, 1982, p, 6)

No respeitante aos critérios de selecção dos jogos, a classificação dos jogos em função de semelhanças estruturais proposta por Ellis(40): jogos de alvo (golfe, bowling, bilhar), jogos de rede/parede (ténis, badminton, squash, voleibol), jogos de batimento (basebol, softball, criquet) e jogos de invasão ou territoriais (futebol, basquetebol, andebol, rugby), veio permitir um mapeamento coerente dos diversos tipos de jogos, com consequências evidentes quer ao nível de uma busca deliberada dos efeitos de uma prática transferível, quer ao nível da racionalização do currículo do ensino dos jogos(19, 22, 45). No primeiro caso, trata-se de dispor jogos e formas do jogo pertencentes a um mesmo tipo de jogo numa ordenação de complexidade crescente de modo a facilitar o desenvolvimento da aprendizagem pela acentuação e tomada de consciência dos princípios de jogo comum, facultando deste modo a transferência das estratégias de leitura das situações de jogo e de busca de soluções para problemas com similaridade estrutural $(37,65,84,116$, 117). No segundo caso trata-se de estabelecer crité 
rios não meramente casuísticos para a colocação dos jogos nos currículos $(22,85,169)$, a sua articulação horizontal (selecção jogos para um determinado nível de escolaridade) e vertical (sucessão e articulação dos jogos ao longo da escolaridade). Mitchell, Oslin e

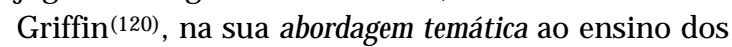
jogos para as idades infantis (primeiro e segundo ciclos do ensino básico), propõem que se deixe de lado as abordagens centradas em modalidade singulares, o futebol, o basquetebol, o hóquei-em-campo, tratadas separadamente, para passar a tratá-las em conjunto, como membros de uma classe de jogos, focando a atenção da aprendizagem sobre os aspectos comuns e transferíveis de jogo para jogo. Em termos práticos, os autores propõem formatos de jogos pré-desportivos para uma dada classe de jogos (ex. jogos de invasão), a partir dos quais os mesmos problemas tácticos (os temas de ensino) possam ser concretizados em formas de jogo particulares que se distinguem por usarem objectos de jogo de diferentes tamanhos e feitios, por estipularem diferentes modos de jogar e, por conseguinte, requisitarem diferentes habilidades motoras.

O modelo TGFU acolheu perfeitamente as ideias construtivistas sobre o papel do aluno no processo de aprendizagem, colocando-o numa posição de construtor activo das suas próprias aprendizagens, val orizando os processos cognitivos, de percepção, tomada de decisão e compreensão(16).

Correlativamente, o modelo adere bem a um estilo de ensino de descoberta guiada(37), em que o aluno é exposto a uma situação problema (a forma de jogo com os seus problemas tácticos) e é incitado a procurar soluções, a verbalizá-las, a discuti-las, a explicá-las, ajudado pelas questões estratégicas do professor, com o objectivo de trazer a equação do problema e respectivas soluções para um nível de compreensão consciente e de acção deliberadamente táctica no jogo. O papel do professor consubstancia-se nas seguintes funções(174): (a) o professor estabelece a forma de jogo; (b) o professor observa o jogo ou a exercitação; (c) o professor e os alunos investigam o problema táctico e as potenciais soluções (exercitação referenciada ao jogo); (d) o professor observa o jogo; (e) o professor intervêm para melhorar as habilidades (se necessário); o professor observa o jogo e intervém para ensinar.
O envolvimento cognitivo, no entanto, não deve alienar o propósito primeiro do modelo: “The primary purpose of teaching any game should be to improve students' game performance and to improve their enjoyment and participation in games, which might lead to a more healthy lifestyle"(178).

Desde o seu aparecimento formal em 1982, o modelo TGfU tem vindo a posicionar-se num lugar de charneira a nível mundial no que diz respeito à investigação e à formação no âmbito do ensino dos jogos desportivos. Os esforços de internacionalização do modelo aconteceram de imediato com participação nos congressos da AIESEP em 1983, Roma(167), e em 1984, Eugene, EUA (169). Em 1986, com a edição do livro Rethinking Games Teaching, Thorpe, Bunker e Almond, com o contributo de outros autores, consolidam as bases conceptuais do modelo, no que respeita à selecção e modificação dos jogos ou à estruturação do processo de ensino e aprendizagem(170).

Na década de 1990, com o ocaso crescente da investigação de pendor behaviorista e o crescimento da influência das correntes cognitivistas e construtivistas, com o seu foco no processamento da informação, na tomada de decisão e na construção do conhecimento, os temas da táctica passam a constar da nova agenda da literatura relacionada com o ensino da educação física. O TGfU, com a sua orientação para a compreensão, para a táctica, para a tomada decisão, estava disponível para receber e enquadrar os contributos destas novas perspectivas. Poderemos destacar, o esforço sustentado de enriquecimento do modelo, através da publicação de ensaios, da elaboração de propostas e instrumentos didácticos, ou da implementação de programas de formação e a institucional ização de uma conferência internacional TGfU.

O Journal of Phyical Education, Recreation and Dance (JOPERD), uma revista essencialmente orientada para a comuni dade de professores de educação física, publica com regularidade artigos relacionados com o TGfU, incluindo a organização de números especialmente dedicados ao tema(9, 12, 19, 26, 27, 34, 37, 62, $65,83,116,126,132,149$ ).

Linda Griffin, Stephan Mitchell e Judith Oslin publicaram dois manuais de referência o "Teaching sport concepts and skills: a tactical games approach"(69) e 
o "Sport foundations for elementary physical education: a tactical games approach"(120). Estes autores desenvolveram e validaram um instrumento de avaliação da partici pação e desempenho dos alunos no jogo, o Game Performance A ssessment Instrument (GPAI)(127) e têm procurado validar a sua abordagem táctica ao ensino dos jogos através de estudos experimentais $(70,119)$.

Outros recursos importantes para fazer o balanço e apreciar as tendências de desenvolvimento da investigação e da reflexão teórica e das propostas práticas sobre o TGfU são os livros "Teaching games for understanding in physical education and sport"(21), que resultou da primeira edição da conferência TGfU, em 2001, e mais recentemente "Teaching Games for Understanding: theory, research, and practice" (67). Recentemente também, a revista Physical Education and Sport Pedagogy publicou um número dedicado ao TGfU, editado por Richard Light(101) e constituído por artigos desenvolvidos a partir de apresentações à conferência TGfU de Melbourne $(2,20,64,66,102,130)$. O rastreio das conferências internacionais TGfU (ver materiais acessíveis em http://www.tgfu.org/index.htm) dá-nos conta do vigor e da natureza das questões que preocupam e atraem investigadores e práticos relativamente ao ensino dos jogos. Curiosamente, a realização da $2^{\underline{a}}$ conferência, em 2003, em Melbourne, Austrália, da 3a conferência em 2005, em Hong Kong, China, e da Asia Pacific Conference on Teaching Sport and Physical Education for Understanding, em 2006, em Sydney parece ter deslocado o centro de gravidade do TGfU para o outro lado do mundo. Ainda que a 4⿳亠丷厂 edição marcada para 2008, em Vancouver, Canadá venha compensar esta tendência.

O modelo TGfU não é um modelo cristalizado, entendido como algo que atingiu a sua forma perfeita e acabada. É um modelo aberto ao diál ogo com diferentes perspectivas teóricas sobre o curriculum, a instrução, a relação pedagógica e a aprendizagem, com preponderância para as diversas perspectivas cognitivistas e construtivistas, mais ligadas às teorias do processamento da informação(15, 68, 174), às perspectivas construtivistas de pendor mais piagetiano ou radical $(19,61,138)$, de pendor mais vygotskiano, social e cultural (33), como a teoria da aprendizagem situada(90, 91, 93, 100, 102).
Desta última perspectiva de aprendizagem situada surgiu uma proposta de revisão do modelo, assinada por Kirk e MacPhail(93, ver Figura 2). Os autores propõem a alteração da designação de al guns elementos do modelo inicial e acrescentam focos de interface para aprofundar a relação entre os elementos do modelo numa perspectiva de aprendizagem situada, sucintamente definida pelos autores:

Learning is an active process of engagement with socially organized forms of subject matter, through perceptual and decision-making processes and the execution of appropriate movement responses, individuals bring prior knowledge to learning episodes that contain a (sometimes wide) range of alternative conceptions of a topic. The learner's active engagement with subject matter is embedded within and constituted by layers of physical, sociocultural, and institutional contexts. These contexts include the immediate physical environment of the classroom, gym, or playing field, social interaction between class members, the institutional form of the school, and aspects of culture such as media sport. (93)

Nesta perspectiva é importante que o professor, na selecção da forma de jogo apropriada, se preocupe em apresentar formas de jogo que tenham em conta as concepções que os alunos trazem para a situação de aprendizagem e que possam ser vistas por parte dos alunos como formas de jogo credíveis e autênticas. A compreensão emergente surge assim como uma interface entre a forma de jogo adoptada e o conceito de jogo, cuja função é focar a atenção do professor sobre como ajudar os alunos a estabelecer a ligação entre os propósitos do jogo e a forma modificada de jogo proposta. Os elementos conceito de jogo e pensar estrategicamente substituem os antecessores apreciação do jogo e consciência táctica para vincarem melhor uma ligação entre o conhecimento declarativo e processual, indo além da mera transmissão-aquisição de conhecimento das regras e outros aspectos do jogo, para visar o conhecimento situado e o uso dos conceitos no jogo. A interface percepção de sinais pretende sublinhar a necessidade de fornecer apoio aos alunos, ajudá-los a procurar e identificar os sinais pertinentes, por exemplo de uma boa linha de passe, de uma situação favorável para finalizar, ou criar uma situação de final ização. 


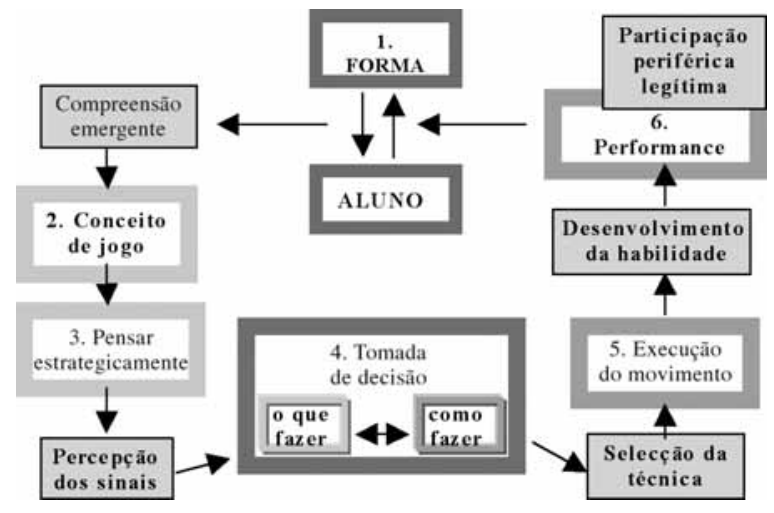

Figura 2. Revisão do modelo TGfU proposta por Kirk e Macphail(93)

Uma boa tomada de decisão, depende de uma boa leitura da situação e esta, por sua vez, depende das competências de busca, de antecipação, de saber o que procurar e onde procurar. As interfaces selecção da técnica e o desenvolvimento da habilidade pretendem reforçar a interligação entre a técnica e a táctica, reconhecendo o carácter situado das habilidades e do seu uso. Uma habilidade nesta perspectiva é mais que uma técnica, é um módulo de aprendizagem que integra em unidade a capacidade de perceber sinais pertinentes, a capacidade estratégica e a capacidade de execução de movimentos. Final mente a performance situada e a interface participação periférica legítima numa comunidade de prática chamam a atenção para a autenticidade e significado das experiências de aprendizagem dos alunos tendo por referência as práticas extra escolares dos jogos enquanto realidades sociais, culturais e institucionais complexas, multifacetadas e heterogéneas. Outro contributo para a revisão do TGfU proveio de Holt, Strean e Bengochea(82), clamando para que o TGfU estenda as suas preocupações ao domínio sócio afectivo, dê espaço à emoção, ao sentimento, ao prazer e não se quede apenas pela compreensão e pela execução do movimento. Em sentido semelhante argumentaram Pope(130), na defesa de uma releitura afectiva do modelo TGfU, e Kretchamar(94), na defesa do domínio subjectivo, do significado da experiência e do deleite, que é mais exigente, mas mais memorável e mais profundo que as experiências divertidas.
O TGfU é um modelo que acomoda diferentes interpretações culturais: Game Sense(16, 99) (Austrália); Game Concept Approach(109) (Singapura); Tactical Approach(69, 120) (EUA); Tactical Decision Making Approach(64) (França). É um modelo que permite explorar entendimentos com outros modelos, como sejam o modelo de educação desportiva $(2,80)$ e o modelo de aprendizagem cooperativa(38, 39). O TGfU tem uma raiz comum com "movement education", porquanto os precursores do TGfU referem a influência das ideias da ginástica educativa de Laban, que estão na base do movement education e enquadram as suas concepções didácticas sobre o ensino dos jogos. Acresce que o TGfU tem beneficiado muito da investigação relativa ao ensino dos jogos e aprender a ensinar inspiradas ou principais proponentes, com destaque para os estudos de Rovegno e colaboradores e de Barrett e colaboradores $(7,8,30,148$ 151), cuja importância, só por si mereceria um tratamento especial.

Entre nós o modelo TGfU e as abordagens tácticas ao ensino dos jogos têm feito parte do labor dos membros do Centro de Estudos dos Jogos Desportivos da Faculdade de Desporto da Universidade do Porto, ao nível da investigação e ensaio teórico, da formação inicial e contínua de professores e treinadores, da produção e divulgação de recursos didácticos, com destaque para a publicação das várias edições do manual "O ensino dos Jogos Desportivos"(50-53), a publicação de vários capítulos no manual "Pedagogia do Desporto"(46, 56, 111, 112, 166), ou ainda a partici pação no projecto europeu Electronic Sport Education Program, do qual resultou a produção de um conjunto de CD-Roms relativos ao modelo de competência nos jogos de invasão (http://www.lo-bsw.ugent.be/ESEP/).

A investigação empírica sobre o TGfU A primeira estratégia de investigação adoptada no estudo do TGfU consistiu na determinação da eficácia relativa deste modelo em comparação com outras abordagens de ensino, através do recurso a desenhos de investigação experimental, dentro de um ambiente geral que opunha as abordagens tácticas às abordagens técnicas(173). Entre as variáveis dependentes figuram medidas relativas à execução das habilidades, à tomada de decisão, ao conhecimento declarati- 
vo ou processual; medidas que são recolhidas em situações descontextual izadas, testes de habilidades estandardizados, testes de papel e lápis ou suporte informático; a partir de imagens de situações reais ou virtuais de jogo; ou ainda a partir da observação do desempenho dos alunos em contexto de jogo. Numa análise crítica a esta investigação, Mcmorris(108) sublinha a escassez de estudos publicados em revistas com revisão de pares, desconsiderando os outros trabal hos por não oferecerem garantias de validade e fiabilidade dos processos de testagem. Os resultados desta linha de investigação, com al gumas excepções, não confirmaram a superioridade das abordagens tácticas sobre as abordagens técnicas ou vice-versa, por exemplo, no que concerne à tomada de decisão (41, no badminton, 42, idem, 118, no futebol, 173, no hóquei em campo), nem no que concerne à execução das habilidades no jogo (41, 42, 43, no squash, 172, no hóquei em campo, 173, idem), ou em testes estandardizados (41, no badminton, 42 , idem, 98, ibidem, 172, 173).

No respeitante ao impacto sobre o conhecimento declarativo e processual dos alunos, os estudos fornecem resultados algo contraditórios. Alguns estudos não revelaram diferenças significativas entre os grupos( $41,42,98,173,174)$. Outros estudos reportaram uma vantagem significativa do $\operatorname{TGFU}(70,118,172)$. Alguns estudos, por contemplarem períodos de instrução demasiado breves, geraram resultados inevitavelmente inconclusi vos dada a falta de tempo para consolidar as de aprendizagens e evidenciar quaisquer efeitos distintivos das abordagens de ensino. Porém, mesmo com abordagens mais longas, os resultados não chegam a ser concludentes. $O$ estudo de Turner(172), com 16 aulas de 45 minutos dedicadas ao ensino do hóquei em campo a alunos do 60 e 70 anos, conseguiu evidenciar vantagens estatisticamente significativas no progresso do grupo TGfU em relação ao grupo da abordagem técnica no conhecimento declarativo do jogo, no controlo da posse de bola e na tomada de decisão. Os grupos não se distinguiram no conhecimento processual e na execução das habilidades no jogo. Numa réplica deste estudo, com 15 aulas de 45 minutos também dedicadas ao ensino do hóquei em campo a alunos do 60 e 70 anos, Turner e Martinek ${ }^{(174)}$ corroboraram parcialmente os resultados anteriores: o grupo TGfU obteve resultados significativamente superiores nas variáveis tomada de decisão relativa ao passe, controlo da bola e execução do passe durante o jogo. Nas restantes medidas reportadas ao jogo, o grupo TGfU apresenta um perfil de evolução mais favorável, mas aquém dos limiares de significância estatística. Já o inverso acontece com os testes técnicos, especialmente no que respeita à velocidade de execução.

O exemplo talvez mais consistente neste tipo de estudo foi realizado por uma equipa de investigadores do qual resultou a publicação de um número monográfico no Journal of Teaching in Physical Education(140), tendo contemplado duas experiências de ensino do badminton a alunos de 9o ano de escolaridade, a primeira com uma duração de 3 semanas ( 15 sessões de 45 minutos) e a segunda com uma duração de 6 semanas ( 30 sessões de 45 minutos). $O$ desenho de investigação constou de grupos experimentais (abordagem táctica - sem ensino explícito da técnica; abordagem técnica - sem ensino explícito da táctica; e abordagem combinada) e um grupo de controlo. Em ambos os estudos, todos os grupos experimentais evoluíram significativamente relativamente ao grupo de controlo. Assim como evoluíram significativamente, no segundo estudo, da avaliação intermédia (final da 3a semana) para a avaliação final. No estudo de 3 semanas não se registaram diferenças entre os grupos no respeitante às medidas relacionadas com o jogo. $\mathrm{O}$ grupo da abordagem combinada obteve resultados mais fracos nos testes técnicos do serviço e do drop, em comparação com os outros grupos. No estudo de 6 semanas, o grupo da abordagem combinada. teve uma evolução mais difícil que os outros grupos. Na avaliação do final da tercei ra semana, apresentava um atraso significativo nas decisões de jogo e na execução das habilidades. No final das seis semanas, recuperou e não se distinguia significativamente dos outros grupos, à excepção do teste técnico do clear. As razões para esta dificuldade podem ter a ver com o facto de o desenho da instrução para este grupo ser mais segmentado, com mais tarefas e com menos tempo por tarefa; pode também ter gerado a dispersão da atenção dos al unos por diferentes aspectos da performance com possibilidades de induzir interferência atencional (42). O facto de o grupo da abordagem táctica não se distinguir do grupo da abordagem técnica sem ter recebido instrução técnica explícita e vice-versa indica 
que os alunos foram capazes de aprender esses aspectos implicitamente. Porventura, o badminton é um jogo cujas tácticas iniciais são simples e evidentes e há uma forte interrelação entre a táctica e a técnica neste jogo. Por outro lado, as situações de resolução de problemas de jogo colocadas pela abordagem táctica podem ter criado as condições para os alunos aplicarem padrões de movimento reportados às diferentes técnicas do badminton.

A dicotomia entre as abordagens tácticas e abordagens técnicas obrigava a introduzir um artificialismo nos estudos que fazia com que nos processos de instrução se evitasse explicitar elementos da abordagem contrária. Ora o TGfU não nega a necessidade do ensino da técnica, apenas sustenta que o trabal ho específico da técnica surja após a apreciação do jogo e a contextualização da sua necessi dade a partir de situações modificadas de jogo. Como bem sublinha Kirk(90): "TGfU has never been about the mere development of tactical awareness. It has always been about developing good game players". O TGfU tem por finalidade desenvolver a capacidade de jogo dos alunos e isso depende do seu conhecimento táctico, da capacidade de perceber e escolher os cursos de acção mais apropriados, assim como da capacidade de executar as acções de jogo. Esta última capacidade tem consequências não apenas ao nível de dar seguimento às leituras e decisões, como, e muito importante, retroage sobre a própria capacidade de leitura dos alunos, ampliando ou reduzindo as possibilidades e disponibilidades de busca, de percepção e de tomada de decisão. Erguer uma barreira entre a técnica e a táctica conduz-nos a uma falsa questão, dado que ambas são importantes para o desempenho no jogo. É necessário ter sempre bem presente que a tomada de decisão é limitada e enviesada por constrangimentos de ordem técnica(44).

Nada do que fica dito pode servir, no entanto, para dar argumentos a favor de uma abordagem tradicional, na qual as técnicas do jogo se apresentam como uma finalidade em si mesmo, sem articulação com o jogo ou com o modo como são requisitadas no jogo praticado pelos alunos. A descontinuidade da abordagem técnica com as necessi dades do jogo fazem desta abordagem um beco sem saída para o ensino do jogo, e a sua conservação, desde há muito tempo criticada, só se percebe como meio para satisfazer o fim do currículo oculto da disciplina e da ordem(90). Se organizar a actividade dos alunos com exercícios e formações fáceis de gerir e controlar dá segurança ao professor e contribui para a eficiência e harmonia da aula, para o busy, happy and good(129), isso não serve de justificação bastante, se que aquilo que se exercita não possuir relevância educativa ou, no caso presente, transferibilidade para a aprendizagem do jogo. A estratégia típica de comparação de abordagens, métodos, estilos, estratégias, ou procedimentos de ensino tem sistemati camente conduzido a resultados inconclusivos, a acusações de enviesamento da investigação, de fomento de generalizações abusivas e de assentar numa concepção inevitavelmente reducionista do processo de instrução(104, 115). Por esta razão, os estudos mais recentes em vez de comparar a superioridade de uns modelos sobre os outros, têm procurado apreciar em maior detalhe o funcionamento dos modelos e reportar os efeitos induzidos por eles e os obstáculos que se levantam à aprendizagem Metzler(115) adverte-nos para que os desenhos e ferramentas de investigação sejam congruentes com o nível de complexidade implicado no estudo dos modelos, pelo que as ferramentas e desenhos de investigação utilizados para o estudo de métodos, estilos e estratégias de ensino não cumprem os requisitos para estudar uma realidade de complexidade superior. Para o autor, não faz mais sentido comparar modelos que à partida se distinguem pelo tipo de resultados de aprendizagem que perseguem, de processos que promovem e de domínios que enfatizam. Será bem mais produtivo estudar a aplicabilidade do modelo e as necessidades de afinamento do modelo em função dos professores, do seu conhe cimento e da sua experiência, em função dos alunos, das suas características, em função da matéria e dos materiais de ensino e aprendizagem, do modo como o conteúdo, as actividades e tarefas podem ser estruturados. Há que ter em conta e estudar em simultâneo as interacções entre a arquitectura do modelo, o conteúdo, o contexto e os resultados.

O desenvolvimento de instrumentos de avaliação contextualizada da qualidade de participação no jogo, nomeadamente o G ame Performance A ssessment Instrument (GPAI) desenvolvido por Oslin, Mitchel e Griffin(127) e o Team Sport A ssessment Procedure (TSAP) desenvolvido por Gréhaigne, Godbout e Bouthier(63) 
vieram abrir novas possibilidades ao estudo das dimensões técnicas e tácticas contextualizadas na situação de jogo, como ainda abrir perspectivas de utilização pedagógica ao serviço do alinhamento da instrução com uma avaliação autêntica(62, 72, 121, 128, 135137). Outras iniciativas de validação e aplicação de instrumentos de avaliação de aspectos críticos do jogo são por exemplo os trabal hos de autores finlandeses(13-15, 105), belgas(162-165) e portugueses $(25,106,107,113)$. Apesar da transferibilidade ser um tema omnipresente no ideário do TGfU, o certo é que não deixa de ser um tema muito pouco investigado. Registe-se o estudo experimental realizado por Mitchell e Oslin(119) para testar a transferibilidade da aprendizagem do badminton para outro jogo de rede tacticamente semelhante, o picleball, e no qual puderam constatar que a compreensão táctica adquirida nas aulas de badminton se transferiam para a compreensão do novo jogo.

Outro aspecto pouco estudado diz respeito à resposta afectiva dos alunos ao TGfU. Dado que a motivação foi desde sempre um dos argumentos a favor do modelo, não deixa de ser uma situação estranha. Tjedersma, Rink e Graham(171) compararam a resposta afectiva de alunos que participaram em unidades de ensino do badminton de 6 semanas (abordagem técnica vs. abordagem tátctica). A experiência foi avaliada como muito positiva por todos os grupos, que não se distinguiram entre si. Wallhead e Deglau(176) investigaram o efeito do TGfU na motivação de 248 alunos com idades compreendidas entre os 10 e os 16 anos (prazer, percepção de esforço, competência percebi da e percepção do envolvimento de aprendizagem. Os resultados revelaram que o modelo proporcionou uma experiencia positiva, não ameaçadora para aceitar desafios, gratificante pela aquisição de competência táctica e intrinsecamente motivante pelo prazer proporcionado pelas actividades de jogo.

Reorientando a investigação sobre o TGfU na direcção de uma aprendizagem situada, Kirk, Brooker e Braiuka(91) preocuparam-se com a interacção entre o conhecimento específico do domínio e o conhecimento estratégico dos alunos, tomando por referência as dimensões física-perceptiva, social-interactiva e institucional-cultural da experiência de aprendizagem situada. Para ilustrar estas três dimensões e o carácter situado das cognições dos alunos, os autores construíram três vinhetas alusivas a incidentes críticos gerados a partir de uma anál ise naturalística baseada na observação, em entrevistas e diários relativos a uma unidade TGfU dedicada ao ensino do basquetebol a estudantes do 8 o ano de escolaridade. Uma outra linha de estudos procurou traçar as particularidades da experiência de aprendizagem do modelo TGfU e dos desafios às concepções pessoais sobre o ensino dos jogos durante a formação inicial, ou a formação em serviço.

Laursen(97) estudou o impacto na al teração da estrutura conceptual sobre os jogos perfilhada por estudantes da formação inicial de professores de educação física, por influência de um programa de 48 sessões de 2 horas dedicado à aprendizagem do modelo TGfU. Utilizando uma abordagem qualitativa, o autor constatou que a generalidade dos estudantes no início do programa já possuía uma estrutura conceptual relativamente compatível com as ideias do TGfU e que no final do programa estavam bem identificados com a estrutura apresentada no programa de formação.

Light e Butler(102) analisaram as histórias de estudantes de Instituições de formação inicial em Educação Física e de professores nos primeiros anos da carreira dos Estados Unidos e Austrália, no respeitante aos seus percursos pessoais de confronto com as ideias e experiências formativas relativas ao TGfU.

Pretenderem os autores explorar o efeito exercido por meios culturais e institucionais distintos no desenvolvimento do programa de formação, na receptivida de, identificação e adesão às perspectivas do modelo TGfU. Os autores destacaram a dimensão afectiva, pessoal, corporizada e não textual implicada na adesão ao modelo: Como referem os autores:

Their stories reveal a personal attachment to TGfU that has been shaped by their own life experiences of sport and physical education and their beliefs about, and dispositions toward, teaching. Certain ways of knowing that are nontextual and embodied are basic to teaching and teacher development. (p.252)

Num estudo semelhante, Light e Tan(103) puseram em evidência a influência de contextos culturais distintos no modo como são vividas e interpretadas as 
experiências formativas relativas ao modelo TGfU/Games Concept Approach no âmbito da formação inicial de professores de educação física na Austrália e em Singapura.

Brooker, Kirk e Braiuka(16) realizaram um estudo de caso relativo à implementação de uma experiência de ensino do basquetebol num contexto natural com alunos do 8 o ano de escolaridade, tendo como protagonista uma professora sem experiência anterior de ensino do modelo. Os autores constaram a dificuldade inerente à mudança conceptual sobre o ensino dos jogos, quando se tem confiança e competência noutro tipo de abordagens e sinalizaram os esforços necessários para ultrapassar os constrangimentos contextuais, como a configuração dos espaços e equipamentos para a aula, as práticas institucionalizadas da educação física na escola, o apoio e colaboração do grupo de educação física.

Graça e Mesquita(49) estudaram as concepções de ensino dos jogos desportivos perfilhadas por professores de educação física envolvidos num programa de formação contínua orientado para uma abordagem inspirada no TGfU. Os autores constataram a existência de concepções distintas para o ensino dos jogos, desde uma mais tradicionalista de ensino das técnicas isoladas e prática da versão completa do jogo, outra similar à progressão desenvolvimentista das fases de desenvolvimento de jogo de Rink(139); e finalmente uma terceira mais aproximada do modelo TGfU, com val orização dos jogos modificados e da precedência dos problemas de jogo, da consciência táctica e tomada de decisão sobre a execução motora, sem deixar de valorizar a contextualização da resposta motora e de colocar no horizonte do ensino o desenvolvimento da capacidade de jogo. Dado que com a experiência os professores vão consolidando as suas concepções de ensino dos jogos e as competências para os ensinar, proceder a uma renovação das concepções e práticas de ensino requer não apenas uma crença firme no valor educativo das novas propostas, capaz de justificar a energia e o investimento pessoal necessários para a mudança, mas também condições de envolvimento e recursos muito favoráveis para assistir, dar apoio e confiança face à instabilidade natural e desconforto que decorre da falta de rotinas e competências específicas requisitadas pelo novo modelo.

\section{O MODELO DE EDUCAÇÃO DESPORTIVA}

A criação e difusão do modelo

Siedentop(158) reporta a génese do modelo de educação desportiva à sua tese de doutoramento que advogava a colocação da educação lúdica (play education) num lugar destacado nas orientações curriculares da educação física. O seu manual Physical Education: Introductory A nalisys, publicado pele primeira vez em 1972, difundiu esta sua visão da educação física, que Jewett e Bain(86) recensearam como modelo curricular autónomo. Foi em 1982 que Siedentop, numa conferência proferida no âmbito do Commonwealth Games, em Brisbane, propôs, pela primeira vez, a criação de Sport Education, na procura da contextualização da sua concepção de play education, através da implementação de ambientes de prática propiciadores de experiências desportivas autênticas; deste modo, pretendia de uma assentada resolver equívocos e mal entendidos na relação da escola com o desporto. Para a expansão deste novo modelo curricular muito contribuíram a inclusão de um capítulo dedicado ao Sport Education no manual "Physical Education: Teaching and curriculum strategies for grades 5-12"(160) e em 1987, " The theory and practice of sport education"(153), nos quais são apresentados os motivos que justificam a sua criação bem como os seus objectivos e características estruturais. A consolidação das bases conceptuais do modelo é conseguida com o lançamento, em 1994, de uma outra intitulada "Sport Education: Q uality P.E. through positive sport experience" (155), que chancelou validação do modelo enquanto ferramenta pedagógica e objecto de indagação científica. Para além de inúmeros workshops nos Estados Unidos da América, (158) e de diversas publicações de carácter didáctico, de ensaio, de reflexão, ou de investigação $(10,11,73,75,89)$, o modelo recoIheu uma aceitação muito favorável e foi al vo de projectos de dimensão nacional na Nova Zelândia(57) e na Austrália(1, 3-5). O SE influenciou programas de Educação Física de diferentes espaços geográficos e culturais do globo, com realce natural para outros espaços de influência anglo-saxónica, como a Inglaterra(29), Hong Kong(88), mas também a Grécia(6), ou a Rússia(81). O recente manual publicado por Siedentop, Hastie e van der Mars(159), "Complete Guide to Sport Education", sistematiza os contributos da experiência acumulada e da investigação em torno do modelo. 
Embora não se circunscreva ao ensino dos jogos, o SE constitui um modelo curricular que oferece um plano compreensivo e coerente para a renovação do ensino dos jogos na escola, preservando e reavivando o seu potencial educativo. Aposta na democratização e humanização do Desporto, de forma a evitar os problemas associados a uma cultura desportiva enviesada, tais como o elitismo, a iniquidade e a trapaça(32). Comporta a inclusão de 3 eixos fundamentais que se revêem nos objectivos da reforma educativa da educação física actual: o da competência desportiva, o da literacia desportiva e o do entusiasmo pelo desporto, sendo o seu propósito formar a pessoa desportivamente competente, desportivamente culta e desportivamente entusiasta. Competente, quer dizer que domina as habilidades de forma a poder participar no jogo de um modo satisfatório e que conhece, compreende e adopta um comportamento táctico apropriado ao nível de jogo praticado. Baseia-se na assunção de que o desempenho competente se relaciona mais com os conteúdos tácticos, os jogos modificados e as progressões de jogos do que com o desenvolvimento das habilidades isoladas(155). Culto, significa que conhece e valoriza as tradições e os rituais associados ao desporto e que distingue a boa da má prática desportiva. Entusiasta, quer dizer que a prática do desporto o atrai e que é um promotor da qualidade e um defensor da autenticidade da prática desportiva. A importância da enfatização do entusiasmo pela prática fundamentase no entendimento de que os níveis de motivação das crianças para a prática desportiva podem ser incrementados quando as componentes afectivas e sociais são expressivamente consideradas, enquanto conteúdo curricular da disciplina de Educação Física(31, 156).

A elevada adesão dos professores à sua inclusão nos programas curriculares de Educação Física foi reforçada pelo apelo a duas linhas de força apontadas para a reforma educativa nos anos 90 , a da educação orientada para resultados autênticos e a da avaliação autêntica(156). Os resultados autênticos evidenciamse numa demonstração cul minante de aprendizagem, reveladora da capacidade de executar uma tarefa até ao fim, com significado contextual, onde estão incluídos os conteúdos, os processos e os meios aplicados. Por sua vez, a avaliação autêntica reporta-se a desempenhos contextual izados, procurando-se um al inhamento da instrução com a avaliação. Deste modo, as práticas de avaliação não suspendem o processo de aprendizagem, são, antes de mais, oportunidades para os alunos aprenderem e exercitarem os resultados desejados e receberem feedback sobre $o$ desenvolvimento da sua aprendizagem.

O SE sustenta a efectivação de uma avaliação autêntica, que se reporta, em primeiro lugar, à capacidade de jogar. A instrução técnica é organizada em função da sua aplicação táctica e é dado tempo suficiente para desenvolver a consciência e a competência táctica. No sentido de garantir a autenticidade das experiências desportivas Siedentop(155) integrou seis características do desporto institucionalizado no Modelo de Educação Desportiva: a época desportiva, a filiação, a competição formal, o registo estatístico, a festividade e os eventos culminantes.

A s épocas desportivas substituem as unidades didácticas de curta duração porquanto o autor argumenta a insuficiência temporal destas para a consolidação das aprendizagens, sendo a época desportiva estendida, pelo menos, por 20 aulas(87). A necessidade de se aumentar o tempo de contacto do aluno com o conteúdo de ensino surge como contraponto à tradicional preferência de currículos sal picados de múltiplas actividades de reduzida duração e de efeitos improváveis. Esta preferência encontrou suporte no argumento de que quanto maior a diversi dade de actividades oferecidas, melhor informado estará o aluno, maior a possibilidade de ir ao encontro das preferências pessoais de cada um, logo maior probabilidade de incluir vol untariamente uma actividade desportiva nos seus hábitos de vida. Todavia, el a é revelado$\mathrm{ra}$, de uma ideologia de activismo inconsequente que vive cada momento presente sem uma ideia de futuro, de transformação, de superação, de desenvolvimento da competência(47).

A filiação promove a integração, no imediato, dos al unos em equipas e, consequentemente, o desenvolvimento do sentimento de pertença ao grupo. A variedade de papéis assumida pelos alunos na constituição das equipas (jogadores, árbitros, jornalistas, dirigentes, etc.) evidencia uma redefinição de papéis do professor e dos alunos, sugerindo a filiação do SE às ideias construtivistas prevalecentes nos anos 90. As equi pas têm nomes, símbolos, cores, capitão, treinador, uma área própria para treinar. 
U ma diferença fundamental do modelo de educação desportiva em relação às abordagens tradicionais é a sua preocupação extrema em diminuir os factores de exclusão, lutando por harmonizar a competição com a inclusão, por equilibrar a oportunidade de participação e por evitar que a participação se reduza ao desempenho de papéis menores por parte dos alunos menos dotados(76). Assim, os critérios de formação de grupos visam assegurar, não apenas o equilíbrio competitivo das equipas, mas também o desenvolvimento das relações de cooperação e entreajuda na aprendizagem(157). Através de uma prática desportiva, na qual é conferida ao aluno iniciativa e valorização do seu desempenho, independentemente do seu nível de habilidade, são criados os pressupostos para que o al uno se sinta confiante, o que, consequentemente, se reflecte no gosto pela prática.

A implementação de um quadro competitivo formal é efectivada logo no início da época pela constituição de equipas, através do estabelecimento de mecanismos promotores da igual dade de oportunidades para participar, nomeadamente pelo premiar da colaboração na aprendizagem e treino no seio de cada equipa. O fair play é enfatizado durante toda a época, havendo pontuação para este aspecto em separado, ou com impacto na pontuação geral da equipa.

Simultaneamente a competição constitui um elemento de auto-avaliação importante e um incentivo para o trabal ho de preparação. Como forma de valorizar a competição, são realizados registos de resultados, comportamentos, estatísticas individuais, ou de equipa que marcam a história e conferem importância ao que se faz na competição.

Cada época tem um evento culminante e procura-se que seja revestido por um carácter festivo. $O$ calendário competitivo prevê normalmente uma sucessão de torneios que, em função do nível da turma, pode nem chegar ao jogo formal. Cada tipo de jogo é configurado nos seus el ementos tácticos estruturantes e respectivas técnicas de suporte. A formulação desses elementos tácticos e técnicos orientarão os processos de preparação das equipas.

Investigação empírica sobre o modelo de educação desportiva

O interesse evidenciado pelos professores na implementação do SE atraiu a atenção dos investigadores, tendo-se assistido nos últimos vinte anos à publicação de mais de sessenta artigos em revistas com revisão de pares(175). Entre os artigos publicados apresentam especial destaque os estudos empíricos sobre o impacto do modelo de educação desportiva nas aprendizagens dos al unos, quer ao nível do conhecimento e desempenho táctico e no domínio das habilidades técnicas como no que se referencia às competências pessoais, afectivas e sociais.

A eficácia da aplicação dos programas de educação desportiva tem mostrado resultados consistentes na participação entusiástica dos alunos(24, 75). Esta evidência é patente, não só, nas convicções dos professores $(5,161)$ e alunos(11), como pela observação sistemática dos alunos(23, 74, 75). Grant et al.(57), e Hastie(75) advogam que a filiação e a responsabilidade conferida aos alunos na tomada de decisões é o factor que mais contribui para o incremento do entusiasmo durante a prática desportiva. Carlson e Hastie(24) evidenciam que uma das maiores singularidades do SE, em relação a outras abordagens, reside no facto dos alunos serem colocados simultaneamente a desempenhar tarefas de ensino e de gestão, papéis tipicamente desempenhados pelo professor, o que lhes exige um maior comprometimento com o desenvolvimento das actividades e com os resultados obtidos. Para o incremento da proficiência dos alunos na real ização destas funções concorre a adopção de sistemas de accountability que regulem e estabilizem as diferentes funções a desempenhar pelos alunos(77).

A filiação tem mostrado ser um dos aspectos mais atractivos do modelo para os al unos(11).

Nomeadamente os al unos menos dotados e as raparigas, habitualmente marginalizados nos programas tradicionais, sentem que, com os programas de educação desportiva, trabalham mais e dão um contributo importante para a equipa; acreditam que aprendem mais e referem que se divertem mais $(23,24,75,76)$. Convicção partilhada também pelos professores(1) fundamentada na assunção de que os alunos menos dotados e as raparigas retiram vantagens significativas do SE ao demonstrarem maior gosto pela prática desportiva e pelo desempenho das tarefas que apoiam a competição. Hastie(74) reporta um impacto positivo dos programas na componente da literacia desportiva e no desempenho sério de papéis de árbitro, anotador e estatístico. Todavia, esta constatação 
não é extensiva às actividades que directamente se relacionam com a actividade motora. Curnow e MacDonald(32), através da análise do comportamento dos alunos durante as aulas mostraram que os rapazes dominaram a posse de bola e desempenharam, durante toda a época desportiva, os papéis mais importantes. A este respeito Hastie(75) faz saber que apesar do SE ter por postulado gerar a inclusão e proporcionar a todos oportunidades iguais de participação, não controla efectivamente a implementação da equidade "... It may have provided equal opportunities for girls to practice and become skillful but it did not overtly address equal ity issues",pp. 169. Segundo Wall head e O'Sullivan(176) um melhor entendimento desta problemática passa, necessariamente, pela realização de investigação longitudinal, que considere a análise de múltiplas aplicações do SE.

A reaç̧ão positiva dos al unos e professores à extensão do tempo dedicada a uma mesma modalidade tem sido evidenciada em diferentes estudos $(4,24,57,74-76)$. No tocante à competência para jogar grande parte dos estudos realizados debruçaram-se sobre as percepções dos professores acerca da eficácia do modeIo(57), bem como nas reflexões dos alunos sobre as experiências de aprendizagem desenvolvidas nas aulas de Educação Física(78, 131). Em ambos os casos os resultados obtidos suportam a pertinência do SE em proporcionar o desenvolvimento do conhecimento do jogo por parte dos alunos, potenciado pela presença da competição ao longo das aulas(5). Estas constatações foram corroboradas por estudos descritivos, com recurso a notas de campo, em diferentes níveis de escolaridade, desde o 5o (131) e 6o ano de escolaridade(78) até ao 9oano de escolaridade(24). São, no entanto, escassos os estudos experimentais focalizados sobre o impacto do SE no incremento do conhecimento e desempenho táctico. Destacam-se dois estudos publicados em revistas com revisão de pares. Um estudo conduzido por Ormond e colaboradores(125) comparou o impacto de um programa de SE e de um programa tradicional no incremento do conhecimento e desempenho táctico dos alunos em Basquetebol. Os autores verificaram maior eficácia do SE sobre o desempenho táctico enquanto que ao nível cognitivo, pela aplicação de testes, antes e após o período instrucional, não houve diferenças entre os dois modelos. $\mathrm{O}$ facto de o estudo ter recorrido a peritos para avaliar o desempenho táctico dos alunos e não aplicar instrumentos de avaliação com sistematização quantificada dos progressos na aprendizagem condiciona a consistência dos resultados obtidos. Posteriormente, Hastie(76) monitorizou o desempenho táctico individual dos jogadores e das equipas numa época de SE de 30 sessões dedicadas à modalidade de ultimate frisbee, pela aplicação de um instrumento de avaliação do desempenho táctico (TSAP) desenvolvido por Gréhaigne e colaboradores(63). O autor verificou que os alunos obtiveram progressos significativos, tanto em acções de recepção da bola como de intercepção. O autor considera a extensão da época desportiva e a manutenção na mesma equipa como principais factores do desenvolvimento da competência táctica e destaca três características da instrução observadas no programa que se associam à melhoria da performance dos alunos: (a) fornecer ao aluno tempo para jogar; (b) ensinar habilidades com transferibilidade para o jogo; (c) fornecer tempo para desenvolver jogadores competentes. Este estudo, por sua vez, como argumentam Wall head e O'

Sullivan(175), apresenta a limitação de utilizar um instrumento de avaliação que não considera as acções de apoio dos atacantes sem bola, que são uma componente táctica fundamental dos jogos de invasão. A ausência de resultados satisfatórios pela aplicação do SE no desenvolvimento das competências tácticas dos alunos pode encontrar explicação no facto do modelo privilegiar as questões do foro social e afectivo, em detrimento dos procedimentos didácticos inerentes ao processo de ensino-aprendizagem.

À semelhança do verificado para a competência táctica também ao nível das habilidades técnicas, a investigação evidencia um claro desencontro entre as percepções dos professores e alunos acerca da eficácia do modelo de educação desportiva e o seu real impacto sobre as aprendizagens. De facto, apesar dos professores $(5,57)$ e alunos advogarem que os alunos progridem mais ao nível técnico pela aplicação do SE relativamente a outras abordagens, os estudos empíricos não validaram esta assunção, principalmente para os alunos de nível de desempenho inferior e para as raparigas(32). Na mesma linha, num estudo de grande extensão realizado por Hastie(76), o autor verificou que os alunos durante 30 aulas de ultimate freebee não registaram progressos, individualmente, 
no passe e na recepção. Mais recentemente, e depois de alguma experiência adquirida na aplicação do modelo, os professores tem vindo a evidenciar algumas reservas sobre a eficácia do SE ao nível das competências motoras. Num estudo desenvolvido por Alexander e Luckman(1), o qual integrou 377 professores australianos, apenas $54 \%$ dos professores concordaram ou concordaram muito que a competência motora é mais incrementada pelo SE do que por outras abordagens. Como referem os autores: "It appears at least while teachers are using the sport education model they believe motor skills are less achievable"

(p.154).

Entre as possíveis explicações para esta fragilidade, Hastie(77) identificou o sistema instrucional do SE, em que um dos alunos desempenha a função de treinador e outros, a de jogadores, como um potencial problema no controlo do conhecimento do conteúdo de ensino. De facto, o desempenho da função de treinador por parte dos alunos exige algum domínio do conteúdo de ensino, porquanto na sua ausência, a prática pode resvalar para experiências ausentes de significado e descaracterizadas em relação aos seus propósitos. Aliás, como refere Hastie (77), alguns treinadores podem ser bons jogadores, o que não significa que sejam capazes de proporcionar experiências qualificadas de prática; nem, tampouco, apresentarem competências para transmitir feedback apropriado em relação aos erros de execução. Siedentop(154), já em 1988, na génese da criação do modelo, e ciente desta dificuldade, alertava para a necessidade de serem utilizadas diferentes estratégias de ensino, incluindo o modelo de instrução directa, a aprendizagem cooperativa, o ensino de pares e adopção de mecanismos de resolução de conflitos, no sentido dos alunos serem preparados para desempenhar funções que dada a sua diversidade e peculiaridade exigem uma preparação prévia. Como refere Graça(48), uma impreparação no modelo de educação desportiva deixará os alunos sem apoio e poderá transformar a aula num recreio supervisionado bem organizado, se o professor possuir boas competências de organização e gestão, dado que este modelo assenta num sistema de organização descentralizado e muito complexo (gestão dos espaços, dos grupos, das competições, dos resultados, dos papeis). Neste sentido, é crucial que a investigação se centre na análise das tarefas de instrução desenvolvidas pelos alunos na função de treinadores durante aplicação do SE, de forma a ser realizado um exame minucioso do conteúdo a ser ensinado e aprendido. Tal poderá possibilitar a indicação de caminhos no desenvolvimento de competências, por parte dos alunos, nas tarefas de ensino enquanto treinadores, sem comprometer a responsabilização e autonomia atribuída aos al unos na tomada de decisões e desenvolvimento das actividades, característica crucial do modelo.

\section{PARA ALÉM DOS MODELOS TGFU E SPORT EDUCATION} Sendo esta revisão centrada sobre dois modelos de ensino dos jogos, o TGfU e o SE, é natural que os autores ou os contributos que não visem directamente estes dois modelos tendam a ficar excluídos da revisão. Porém, dada a influência que al guns autores e estudos exercem na conceptual ização e investigação da problemática do ensino e da aprendizagem dos jogos, esquecê-los é de todo injustificado. Inez Rovegno não se identifica formalmente com o TGfU. Porém, a matriz conceptual da concepção de ensino que perfilha revê-se perfeitamente no núcleo de preocupações fundamentais da TGfU - o jogo como espaço de problemas, o aluno como construtor activo da sua aprendizagem, a importância da compreensão e da tomada de decisão. A sua investigação, a partir de uma perspectiva construtivista da aprendizagem, sobre os problemas de aquisição e desenvolvimentos de conhecimento pedagógico do conteúdo sobre o ensino dos jogos, de corte com as abordagens tradicionais, especialmente, mas não exclusivamente, no âmbito da formação de professores,(142-147, 150); e a investigação em equipa sobre o ensino dos jogos de invasão a alunos do 40 ano de escolaridade, publicada em 2001, num número monográfico do Journal of Teaching in Physical Education (123, 124, 151, 152) são assumidas como contributos fundamentais, tanto nos aspectos teóricos como nos metodológicos, pelos adeptos do TGfU. Metzler(114, 115) e Kirk ${ }^{(90,92)}$ acreditam que a educação física terá muito a ganhar se os modelos se afirmaram no quotidiano das escolas e do trabal ho dos professores e dos alunos. Apesar do grau de sofisticação a que chegaram estes dois modelos, apesar da qualidade e quantidade de materiais e recursos di dácticos e apesar da base de investigação que val i- 
dam e credi bilizam os modelos, muito há ainda para percorrer para transformar aquele desejo e fundada expectativa em realidade.

Entretanto, têm vindo a emergir, pelo caminho, novas tendências quer no sentido da diversidade, quer no sentido da confluência e aproximação de modelos. Ainda que contraditórias estas duas tendências são não apenas desejáveis como necessárias para evitar a cristalização e o formalismo das ideias e das práticas de ensino dos jogos.

Um movimento de confluência entre o SE e o TGfU tem vido a esboçar-se em diversos quadrantes e a diversos níveis. Por exemplo, a simpatia de Kirk(91-93) pela congruência dos dois modelos com uma concepção situada da aprendizagem dos jogos, assente na valorização conjunta das dimensões física-perceptiva, social-interactiva e institucional-cultural contribui para legitimar esta aproximação. Outros autores argumentaram a favor da conjugação das potencialidades dos dois modelos $(2,35,38,39)$.

Tem vindo a crescer o número de estudos empíricos sobre experiências de conjugação dos modelos TGfU e SE quer entre si, quer com outros modelos e os resultados têm permitido extrair al gumas conclusões interessantes e levantar novas questões $(17,79,80)$. Hastie e Curtner-Smith(80), num estudo aplicado na Austrália, e que envolveu 29 alunos do 60 ano de escolaridade, pretenderam descrever as experiências de ensino e a reacção dos alunos a um programa de ensino híbrido baseado no TGFU e no SE, durante um período de 5 semanas. Este estudo teve a particularidade de se constituir uma experiência de ensino leccionada pelo investigador principal do estudo. Os autores constataram que a aplicação combinada dos dois modelos não fragilizou qualquer das vantagens de cada um deles, embora se verificasse uma maior tendência para o professor assumir maior protagonismo na orientação das actividades e consequentemente a sua participação ser mais intensiva. Os autores acautelam a necessidade dos professores possuírem um forte domínio do conhecimento pedagógico do conteúdo na aplica ção de um programa de ensino híbrido o qual integre a combinação do TGFU e o SE.

O modelo de competência nos jogos de invasão( 54,55 , 122), ainda que conceptualmente mais próximo do TGfU, procura acolher as ideias do modelo de educação desportiva no que respeita a aspectos de organi- zação da experiência desportiva dos alunos no que diz respeito aos elementos que favorecem a criação de um contexto desportivo autêntico. Ricardo $(133,134)$ desenvolveu um estudo experimental de validação deste modelo de ensino, tendo desenvolvido uma época desportiva de 25 aulas de 45 minutos dedicada ao ensino basquetebol a alunos do 9o ano de escolaridade. Os alunos do grupo experimental (39) e do grupo de controlo(18) foram pré e pós avaliados nas variáveis conhecimento táctico declarativo (teste escrito) e desempenho em jogo relativo à tomada de decisão, à execução motora e ao resultado da acção das acções ofensivas dos alunos. A unidade de ensino de basquetebol contribui para a melhoria significativa do grupo experimental nas variáveis tomada de decisão em jogo, execução motora e resultado da aç̧ão Os alunos de nível de entrada mais baixo demonstraram ter aproveitado o período de instrução para melhorar as suas acções ofensivas em dois aspectos críticos do jogo, o passe e os movimentos sem bola.

Com a publicação do manual "Play practice: the games approach to teaching and coaching" Launder(96) desenvolve uma alternativa de ensino, também ela centrada no jogo, na contextualização dos problemas tácticos, mas com uma interacção que pretende ser mais imediata e íntima dos aspectos técnicos e tácticos, em observância de uma dinâmica interna de estruturação e sequência marcadas pela ideia de alinhamento da prática com o jogo.

Considerando outros desenvolvimentos mais distantes, mas ainda assim centrados na ideia de jogo, de aprendizagem situada em contextos de prática autênticos, surge-nos a "Escola da Bola" proposta e investigada por Roth e colaboradores $(95,110,141)$ e divulgada entre nós por Pablo Greco(58-60), privilegiando o desenvolvimento da inteligência e da criatividade, das capacidades de pensamento convergente e divergente na tomada de decisão táctica, através de uma abordagem que designam de não específica para desenvolver as competências básicas nos domínios tácticos, coordenativos e técnicos.

Uma outra perspectiva (ou grel ha de leitura?) pretende constituir uma pedagogia não linear $(28,36)$ a partir da perspectiva ecológica da aprendizagem motora, que considera a interacção de constrangimentos organismo-tarefa-envolvimento. Uma manipulação judiciosa dos constrangimentos e uma identificação dos princi- 
pais constrangimentos individuais permitirá envolver os alunos num processo de exploração e auto-descoberta de soluções para os movimentos.

\section{CONCLUSÃO}

Os modelos de ensino dos jogos para a compreensão (TGfU) e de educação desportiva (SE) têm evidentes pontos de contacto, al guns aspectos que se podem complementar e outros que são mais ou menos manifestamente divergentes. Os model os coincidem na crítica ao currículo de múltiplas actividades, pelo seu carácter descontextualizado e inconsequente, sendo que ambos favorecem os jogos reduzidos e a contextualização das situações de jogo(80). Apesar do SE possuir pontos de convergência com o TGfU demarcam-se em duas vertentes: enquanto que o SE é sobretudo um modelo de ensino que visa a valorização da dimensão humana e cultural do Desporto(158), o TGFU realça as competências dos praticantes para o domínio do jogo(80). Ambos dão importância à componente táctica do jogo, embora o TGfU pareça envolver uma componente cognitiva mais acentuada por parte do aluno. Particularmente, O TGFU é mais elaborado nos critérios que presidem à determinação das formas modificadas de jogo e da respectiva evolução. Por sua vez, o modelo de educação desportiva visa uma socialização desportiva mais completa, abrangendo papéis diversificados e um leque de responsabilidades mais vasto a assumir pelos alunos.

Ambos os modelos dependem criticamente do conhecimento pedagógico do conteúdo que o professor possui a respeito dos jogos. Uma impreparação no TGFU transformará as aulas num formalismo de questões abstractas ou irrelevantes para os reais problemas tácticos, nada contribuindo para os ajudar a ler o jogo de uma forma tacticamente mais inteligente. Um e outro modelo são al ternativas comprovadamente válidas às abordagens tradicionais ao ensino dos jogos desportivos, mas não esgotam, nem tão pouco pretendem monopolizar as alternativas válidas ou auspiciosas para o ensino dos jogos. Têm-se aberto possibilidades de cooperação criativa e mutuamente enriquecedora entre modelos, têm-se ensaiado desenvolvimentos diferenciados dos modelos para responder a contextos culturais, sociais e institucionais distintos bem como a agendas com problemas e propósitos diferenciados.
A investigação empírica relacionada com ambos os modelos tem vindo a crescer e a diversificar-se tanto no que diz respeito ao ângulo ou ângulos de abordagem (ensino, aprendizagem, currículo), aos sujeitos e tópicos destacados (ex. o aluno: concepções pessoais, conhecimento declarativo ou processual, tomada de decisão, execução motora, motivação, afectividade; o professor ou candidato a professor: concepções e percursos pessoais e disposições para a aprendizagem e a mudança, conhecimento pedagógico do conteúdo); às perspectivas teóricas (ex. teorias do processamento da informação, construtivistas, da cognição situada, dos sistemas dinâmicos e dos constrangimentos) e metodológicas (ex. abordagens qualitativas e quantitativas, estudos de casos, estudos experimentais).

Este crescimento exige também mai or sofisticação. Metzler(115) adverte-nos para que os desenhos e ferramentas de investigação sejam congruentes com o nível de complexidade implicado no estudo dos modelos, pelo que as ferramentas e desenhos de investigação utilizados para o estudo de métodos, estilos e estratégias de ensino não cumprem os requisitos para estudar uma realidade de complexidade superior. Para o autor, não faz mais sentido comparar model os que à partida se distinguem pelo tipo de resultados de aprendizagem que perseguem, de processos que promovem e de domínios que enfatizam. Será bem mais produtivo estudar a aplicabilidade do modelo e as necessidades de afinamento do modelo em função dos professores, do seu conhecimento e da sua experiência, em função dos alunos, das suas características, em função da matéria e dos materiais de ensino e aprendizagem, do modo como o conteúdo, as actividades e tarefas podem ser estruturados. Há que ter em conta e estudar em simultâneo as interacções entre a arquitectura do modelo, o conteúdo, o contexto e os resultados.

\section{CORRESPONDÊNCIA}

\section{Amândio Graça}

Gabinete de Pedagogia do Desporto

Faculdade de Desporto, Universidade do Porto

Rua Dr. Plácido Costa, 91

4200-450 Porto, Portugal

E-mail: agraca@fade.up.pt 


\section{REFERÊNCIAS}

1. Alexander K, Luckman J (2001). Australian teachers' perceptions and uses of the sport education curriculum model. European Physical Education Review 7:243

2. Alexander K, Penney D (2005). Teaching under the influence: feeding Games for Understanding into the Sport Education development-refinement cycle. Physical Education and Sport Pedagogy 10:287-301

3. Alexander K, Taggart A, Luckman J (1998). Pilgrims progress. JOPERD: The Journal of Physical Education, Recreation \& Dance 69:21

4. Alexander K, Taggart A, Medland A (1993). Sport education in physical education: try before you buy. ACH PER $N$ ational Journal 40:16-23

5. Alexander K, Taggart A, Thorpe S (1996). A Spring in their Steps? Possibilities for Professional Renewal through Sport Education in Australian Schools. In:Routledge, p 23 - 46

6. Andreou N, Tsangaridou N (2001). The procedure and the knowledge from the application of the sport education model in elementary school. Athlitiki Psychologia 12:49-59

7. Barrett KR, Collie S (1996). Children learning lacrosse from teachers learning to teach it: the discovery of pedagogical content knowledge by observing children's movement. Research Quarterly for Exercise and Sport 67:297-309

8. Barrett KR, Turner AP (2000). Sandy's Challenge: New Game; New Paradigm. Journal of Teaching in Physical Education 19:162-181

9. Belka DE (1998). Strategies for teaching tag games. JOPERD 69:40-43

10. Bell C (1998). Sport education in the elementary school. JOPERD 69:36-39; 48

11. Bennett G, Hastie P (1997). A sport education curriculum model for a collegiate physical activity course. JOPERD 68:39-44

12. Berkowitz RJ (1996). A practitioner's journey: from skill to tactics. JOPERD 67:44-45

13. Blomqvist M, Luhtanen P, Laakso L (1998). Validation of a notational analysis system in badminton. Journal of Human M ovement Studies 35:137-150

14. Blomqvist $M$, Vänttinen $T$, Luhtanen $P$ (2005). Assessment of secondary school students' decision-making and game-play ability in soccer. Physical Education \& Sport Pedagogy 10: 107-119

15. Blomqvist MT, Luhtanen P, Laakso L, Keskinen E (2000). Validation of a video-based game-understanding test procedure in badminton. Journal of Teaching in Physical Education 19:325-337

16. Brooker R, Kirk D, Braiuka S, Bransgrove A (2000). Implementing a game sense approach to teaching junior high school basketball in a naturalistic setting. European Physical Education Review 6:7-25

17. Browne $T$ (2003). Teaching games through sport education and games sense: an extended case study of high school physical education. (Abstract). In: In 2 nd International conference: teaching sport and physical education for understanding, Melbourne, Vic., University of Melbourne, 2003, p.33., Australia

18. Bunker D, Thorpe R (1982). A Model for the Teaching of Games in Secondary Schools. In: Bulletin of Physical Education. p 5-8

19. Butler J (1997). How would Socrates teach games? A constructivist approach. JOPERD 68:42-47
20. Butler J (2005). TGfU pet-agogy: old dogs, new tricks and puppy school. Physical Education and Sport Pedagogy 10:225 240

21. Butler J, Griffin L, Lombardo B, Nastasi R (eds). (2003). Teaching Games for Understanding in Physical Education and Sport. National Association for Sport and Physical Education, Reston; VA

22. Butler J, McCahan BJ (2005). Teaching games for understanding as a curriculum model. In: Griffin LL, Butler J (eds) Teaching Games for Understanding : theory, research, and practice. Human Kinetics, Champaign, IL, p 33-54

23. Carlson TB (1995). We hate gym: Student alienation from physical education. Journal of Teaching in Physical Education 14:467-477

24. Carlson TB, Hastie P (1997). The student social system within Sport Education. Journal of Teaching in Physical Education 16:176-195

25. Castro A, Mesquita I, Pereira F (2007). Análise do jogo $1 \times 1$ e $2 \times 2$ no contexto escolar. In: Actas do 10 congresso Internacional de Jogos D esportivos - O Ihares e contextos da performance. $\mathrm{Da}$ iniciação ao Rendimento (CD-ROM). Centro de estudos de jogos desportivos, Faculdade de Desporto, Universidade do Porto, Porto

26. Chandler T (1996). Teaching games for understanding: reflections and further questions. JOPERD 67:49-51

27. Chandler T, Mitchell S (1990). Reflections on models of games education. JOPERD Journal of physical Education Recreation and Dance 61:19-21

28. Chow JY, Davids K, Button C, Shuttleworth R, Renshaw I, Araujo D (2007). The role of Nonlinear pedagogy in physical education. Review of Educational Research 77:251-278

29. Clarke G, Quill M (2003). Researching sport education in action: a case study. European Physical Education Review 9:253-266

30. Connolly M (1991). Teaching games from a movement education perspective. In: In, Bell, F.I. and Van Gyn, G.H. (eds.), Proceedings for the 10 th Commonwealth $\&$ International Scientific Congress: access to active living, 10-14 August 1994, University of Victoria, Victoria, B.C., Victoria, University of Victoria, 1994, p. 487-488., Canada

31. Corbin CS (2002). Physical activity for everyone: What every physical educator should know about promoting lifelong physical activity. Journal of Teaching in Physical Education 21:128-144

32. Curnow J, Macdonald D (1995). Can sport education be gender inclusive? A case study in upper primary school. The ACH PER H ealthy Lifestyles Journal 42:9-11

33. Curry C, Light R (2007). Addressing the NSW quality teaching framework in physical education: Is Game Sense the answer? In: Light R (ed) Proceedings for the A sia Pacific Conference on Teaching Sport and Physical Education for Understanding. The University of Sydney, Sydney, Australia, p 7-19

34. Curtner-Smith MD (1996). Teaching for understanding: using games invention with elementary children. JOPERD 67:33-37

35. Curtner-Smith MD (2004). A Hybrid Sport EducationGames for Understanding Striking/Fielding Unit for Upper Elementary Pupils. Teaching Elementary Physical Education $15: 7$

36. Davids K, Chow JY, Shuttleworth R (2005). A Constraintsbased Framework for Nonlinear Pedagogy in Physical 
Education Journal of Physical Education New Zealand 38:17-29

37. Doolittle S (1995). Teaching net games to skilled students: A teaching for understanding approach. JOPERD The Journal of Physical Education Recreation \& Dance 66:18-23

38. Dyson B (2005). Integrating cooperative learning and tactical games models: Focusing on social interactions and decision making. In: Griffin LL, Butler J (eds) Teaching Games for Understanding : theory, research, and practice. Human Kinetics, Champaign, IL, p 149-168

39. Dyson B, Griffin LL, Hastie P (2004). Sport Education,Tactical Games, and Cooperative Learning: Theoretical and Pedagogical Considerations. Q uest (Human Kinetics) 56:226-240

40. Ellis M (1983). Similarities and differences in games: a system for classification. In: International AIESEP Congress, Teaching Team Sports. Rome

41. French K, Werner P, Rink J, Taylor K, Hussey K (1996). The Effects of a 3 - Week Unit of Tactical; Skill; or Combined Tactical and Skill Instruction on Badminton Performance of Ninth- Grade Students. Journal of Teaching in Physical Education 15:418-438

42. French K, Werner P, Taylor K, Hussey K, Jones J (1996). The Effects of a 6 - Week Unit of Tactical; Skill; or Combined Tactical and Skill Instruction on Badminton Performance of Ninth- Grade Students. Journal of Teaching in Physical Education 15:439-463

43. Gabriele TE, Maxwell T (1995). Direct versus indirect methods of squash instruction. Abstract. R esearch Q uarterly for Exercise and Sport 66 (Suppl.):A-63

44. Gallagher JD, French KE, Thomas KT, Thomas JR (1996). Expertise in youth sport: relations between knowledge and skill. In: F.L. S, R.E. S (eds) Children and youth sport: a biopsychosocial perspective. Brown \& Benchmark, Madison; Wis., p 338-358

45. Garganta J (1995). Para uma teoria dos jogos desportivos colectivos. In: Graça A, Oliveira J (eds) 0 ensino dos Jogos Desportivos. CEJD/FCDEF-UP, Porto, Portugal, p 11-25

46. Garganta J (2006). Ideias e competências para pilotar o jogo de futebol. In: Tani G, Bento JO, Petersen RS (eds) Pedagogia do desporto. Guanabara Koogan, Rio de Janeiro, $p$ 313-326

47. Graça A (2001). Concepções didácticas do ensino do jogo. In: I Congreso I bérico de Baloncesto. Facultad de Ciencias del Deporte de la Universidad de Extremadura, Caceres; Espanha

48. Graça A (2002). Concepções didácticas sobre o ensino do jogo. In: Ibañez-Godoy S, Macías-García M (eds) N ovos horizontes para o treino do basquetebol. Faculdade de Motricidade Humana, Universidade Técnica de Lisboa, Cruz Quebrada, p 21-36

49. Graça A, Mesquita I (2003). Physical Education teachers' conceptions about teaching TGfU in portuguese schools. In: Butler J, Griffin L, Lombardo B, Nastasi R (eds) Teaching Games for Understanding in Physical Education and Sport. National Association for Sport and Physical Education, Reston; VA, p 87-97

50. Graça A, Oliveira J (eds) (1994). 0 ensino dos jogos desportivos. Centro de Estudos dos Jogos Desportivos, Faculdade de Ciências do Desporto e de Educação Física da Universidade do Porto, Porto

51. Graça A, OliveiraJ (eds) (1995). 0 ensino dos jogos desportivos. Centro de Estudos dos Jogos Desportivos,
Faculdade de Ciências do Desporto e de Educação Física da Universidade do Porto, Porto

52. Graça A, Oliveira J (eds) (1997). La ensenanza de los juegos deportivos. Paidotribo, Barcelona

53. Graça A, Oliveira J (eds) (1998). 0 ensino dos jogos desportivos. Centro de Estudos dos Jogos Desportivos, Faculdade de Ciências do Desporto e de Educação Física da Universidade do Porto, Porto

54. Graça A, Pinto D (2005). Modelo de competência nos jogos de invasão aplicado ao ensino do basquetebol. In: Martinez de Santos R (ed) Libro de actas do III Congreso Ibérico de Baloncesto: modelos para un baloncesto de calidad. Avafiep-Fiepzaleak Vitoria, p 154

55. Graça A, Pinto D, Mertens B, Multael M, Musch E, Timmers E, Meertens T, Taborsky F, Remy C, Vonderlynck V, De Clercq D (2006). M odelo de competência nos jogos de invasão: U ma ferramenta didáctica para 0 ensino do basquetebol. Estudos CEJD 6:7-28

56. Graça A, Ricardo V, Pinto D (2006). O ensino do basquetebol: aplicar o modelo de competência nos jogos de invasão criando um contexto desportivo autêntico. In: Tani G, Bento JO, Petersen RS (eds) Pedagogia do desporto. Guanabara Koogan, Rio de Janeiro, p 299-312

57. Grant BC (1992). Integrating sport into the physical education curriculum in New Zealand secondary schools. Quest (00336297) 44:304-316

58. Greco PJ (2004). Cogni (a) ção: caracterização e avaliação dos processos cognitivos subjacentes à tomada de decisão nos jogos esportivos coletivos. Bulletin FIEP Foz Iguaçu

59. Greco PJ (2006). Conhecimento técnico-tático: o modelo pendular do comportamento e da ação tática nos esportes coletivos R evista Brasileira de Psicologia do Esporte e do Exercício 0:107-129

60. Greco PJ (2007). Tomada de decisão nos jogos esportivos coletivos: O conhecimento tático-técnico como eixo de um modelo de pêndulo. In: $1^{\circ}$ Congresso Internacional de Jogos Desportivos: Olhares e contextos da performance - da iniciação ao alto rendimento. Faculdade de Desporto, Universidade do Porto, Porto

61. Gréhaigne J-F, Godbout P (1995). Tactical Knowledge in Team Sports from a Constructivist and Cognitivist Perspective. Quest 47:490-505

62. Gréhaigne J-F, Godbout $P$ (1998). Formative Assessment in Team Sports in a Tactical Approach Context. JOPERD 69:46-51

63. Gréhaigne J-F, Godbout P, Bouthier D (1997). Performance assessment in team sports. Journal of Teaching in Physical Education 16:500-516

64. Gréhaigne JF, Wallian N, Godbout P (2005). Tactical-decision learning model and students' practices. Physical Education and Sport Pedagogy 10:255 - 269

65. Griffin L (1996). Tactical Approaches to Teaching Games: Improving Net/Wall Game Performance. JOPERD 67:3437

66. Griffin LL, Brooker R, Patton K (2005). Working towards legitimacy: two decades of teaching games for understanding. Physical Education and Sport Pedagogy 10:213-223

67. Griffin LL, Butler J (2005). Teaching Games for Understanding : theory, research, and practice. Champaign, IL: Human Kinetics

68. Griffin LL, Dodds P, Placek JH, Tremino F (2001). Middle school students' conceptions of soccer: their solutions to 
tactical problems. Journal of Teaching in Physical Education 20:324-340

69. Griffin LL, Mitchell SA, Oslin JL (1997). Teaching sport concepts and skills : a tactical games approach. Champaign, IL: Human Kinetics

70. Griffin LL, Oslin JL, Mitchell SA (1995). An analysis of two instructional approaches to teaching net games (abstract). Research Q uarterly for Exercise and Sport 66:A-64

71. Griffin LL, Patton K (2005). Two decades of Teaching Games for Understanding: looking at the past, present, and future. In: Griffin LL, Butler J (eds) Teaching Games for Understanding : theory, research, and practice. Human Kinetics, Champaign, IL, p 1-17

72. Harvey S (2006). Effects of Teaching Games for Understanding on game performance and understanding in middle school physical education. In:Oregon State University, Oregon, p 285

73. Hastie P (1996). Research on sport education: current findings and future possibilities. In: In Naul, R. (ed.), International Council of Sport Science and Physical Education (ICSSPE), Physical activity and active lifestyle of children and youth, Schorndorf, Verlag Karl Hofmann, 1998, p.147-151., Germany, Federal Republic of

74. Hastie P (1996). Student role involvement during a unit of sport education. Journal of Teaching in Physical Education 16:88-103

75. Hastie $P$ (1998). The participation and perceptions of girls within a unit of sport education. Journal of Teaching in Physical Education 17:157-171

76. Hastie P (1998). Skill and tactical development during a sport education season. Research Q uarterly for Exercise and Sport 69:368-379

77. Hastie P (2000). An ecological analysis of a sport education season. Journal of Teaching in Physical Education 19:355373

78. Hastie P, Buchanan A (2000). Teaching Responsability Through Sport Education: Prospects of a Coalition. Research Quarterly for Exercise and Sport 71:25-35

79. Hastie P, Buchanan AM (2000). Teaching responsibility through sport education: prospects of a coalition. Research Q uarterly for Exercise \& Sport 71:25-35

80. Hastie P, Curtner-Smith M (2006). Influence of a hybrid Sport Education - Teaching Games for Understanding unit on one teacher and his students. Physical Education and Sport Pedagogy 11:1-27

81. Hastie P, Sinelinikov OA (2006). Russian students' participation in and perceptions of a season of Sport Education. European Physical Education Review 12:131-150

82. Holt NL, Strean WB, Bengoechea EG (2002). Expanding the teaching games for understanding model: New avenues for future research and practice. Journal of Teaching in Physical Education 21:162-176

83. Hopper T (2002). Teaching Games for Understanding: The importance of student emphasis over content emphasis. JOPERD

84. Hopper T, Bell R (2001). Games classification system: Teaching strategic understanding and tactical awareness. CAHPERD 66:14-19

85. Jackson S (1986). Teaching for understanding in games: A working curriculum 11-16. Bulletin of Physical Education 2:27-30

86. Jewett $A E$, Bain $L L$ (1985). The curriculum process in physical education. Dubuque, lowa: W.C. Brown
87. Jones $D$, Ward $P$ (1998). Changing the face of secondary physical education through sport education. JO PERD 69:40-45

88. Ka Lun C, Cruz A (2006). The Effect of Sport Education on Secondary Six Students' Learning Interest and Collaboration in Football Lessons. Journal of Physical Education \& Recreation (10287418) 12

89. Kinchin G, O'Sullivan M (1999). Making Physical Education Meaningful for High School Students. JO PERD 70:40-44

90. Kirk D (2005). Future prospects for Teaching Games for Understanding. In: Griffin LL, Butler J (eds) Teaching Games for Understanding : theory, research, and practice. Human Kinetics, Champaign, IL, p 213-227

91. Kirk D, Brooker R, Braiuka S (2000). Teaching Games for Understanding: A Situated Perspective on Student Learning. In: A nnual M eeting of the A merican Educational Research A ssociation. New Orleans, LA, p 12

92. Kirk D, Kinchin G (2003). Situated learning as a theoretical framework for sport education. European Physical Education Review 9:221-235

93. Kirk D, MacPhail A (2002). Teaching games for understanding and situated learning: Rethinking the BunkerThorpe model. Journal of Teaching in Physical Education 21:177-192

94. Kretchmar RS (2005). Teaching Games for Understanding and the delights of human activity In: Griffin LL, Butler J (eds) Teaching Games for Understanding : theory, research, and practice. Human Kinetics, Champaign, IL, p 199-212

95. Kroger C, Roth K (2005). Escola da bola São Paulo. Brasil: Phorte Editora

96. Launder AG (2001). Play practice : the games approach to teaching and coaching sports. Champaign, IL ; Leeds: Human Kinetics

97. Laursen P (1996). A Case-Study of Games for Understanding in PETE. In: AIESEP International Seminar. Lisboa

98. Lawton J (1989). Comparison of two teaching methods in games. Bulletin of Physical Education 25:35-38

99. Light R (2000). Making Sense of Games through the Manipulation of Space and Time. In: Science Teachers' A ssociation of Victoria; celebrating $N$ ational science W eek public lecture night;. Shelford Anglican Girls School; Melbourne

100. Light R (2003). Knowing the Game: Integrating Speech and Action in Games Teaching Through TGfU. QUEST 55

101. Light R (2005). Introduction. Physical Education \& Sport Pedagogy 10:211-212

102. Light R, Butler J (2005). A personal journey: TGfU teacher development in Australia and the USA. Physical Education and Sport Pedagogy 10:241 - 254

103. Light R, Tan S (2006). Culture, embodied experience and teachers' development of TGfU in Australia and Singapore. European Physical Education Review 12:99

104. Locke L (1981). Teaching and Learning Processes in Physical Activity: The Central Problem of Sport Pedagogy. In: Haag H (ed) XXII ICH PER W orld Congress. Schorndorf, Verlag Karl Hoffmann, Kiel, p 140-154

105. Luhtanen P, Blomqvist M, Keskinen E, Brown E, Valovirta E (2004). Development and validation of a video based game understanding test in youth soccer. Journal of H uman M ovement Studies 47:47-60

106. Mangas C, Garganta J, Fonseca A (2002). Estudo comparativo do conhecimento declarativo de jovens praticantes de 
Futebol, em função do seu nível competitivo. In: Garganta J, Suarez AA, Peñas CL (eds) A investigação em Futebol. Estudos I béricos. Universidade do Porto: Faculdade de Ciências do Desporto e de Educação Física, Porto, Portugal, p 179-187

107. Mangas C, Garganta J, Fonseca A (2007). Construção, validação e aplicação de um protocolo de conhecimento declarativo no futebol. In: $1^{\circ}$ Congresso Internacional de Jogos D esportivos: Olhares e contextos da performance - da iniciação ao alto rendimento. Faculdade de Desporto - Universidade do Porto, Porto

108. McMorris T (1998). Teaching Games for U nderstanding: Its contribution to the knowledge of skill acquisition from a motor learning perspective. In:Routledge, p 65 - 74

109. McNeill, Fry, Wright, Tan, Tan, Schempp (2004). 'In the local context': Singaporean challenges to teaching games on practicum. Sport, Education and Society 9:3-32

110. Memmert D, Roth K (2007). The effects of non-specific and specific concepts on tactical creativity in team ball sports. In:Routledge, p 1423 - 1432

111. Mesquita I (2006). Ensinar bem para aprender melhor o jogo de Voleibol. In: Tani G, Bento J, Petersen R (eds) Pedagogia do D esporto. Guanabara Koogan, Rio de Janeiro, Brasil, p 327-343

112. Mesquita I, Graça A (2006). Modelos de ensino dos jogos desportivos. In: Tani G, Bento JO, Petersen RS (eds) Pedagogia do desporto. Guanabara Koogan, Rio de Janeiro, $\mathrm{p}$ 269-283

113. Mesquita I, Pinheiro M (2006). Estruturação da competição no treino infanto-juvenil: Avaliação do desempenho no ataque, no jogo $2 \times 2$, no âmbito do projecto GiraVolei em Portugal. In: Garcia E, Lemos K (eds) Temas atuais XI - Educação Física e Esportes. Casa da Educação Física, Belo Horizonte, Brasil, p 27-44

114. Metzler MW (2000). Instructional models for physical education. Boston: Allyn and Bacon

115. Metzler MW (2005). Implications of models-based instruction for research on teaching : a focus on Teaching Games for Understanding. In: Griffin LL, Butler J (eds) Teaching Games for Understanding : theory, research, and practice. Human Kinetics, Champaign, IL, p 183-197

116. Mitchell S (1996). Tactical Approaches to Teaching Games: Improving Invasion Game Performance. JOPERD 67:30-33

117. Mitchell S (2000). A Framework and Sample Games for Go Through-Go To Games. Teaching Elementary Physical Education 11:8

118. Mitchell SA, Griffin LL, Oslin JL (1995). The effects of two instructional approaches on game performance. Pedagogy in Practice: Teaching and Coaching in Physical Education and Sports 1:36-48

119. Mitchell SA, Oslin JL (1998). An Investigation of Tactical Transfer in Net Games. Physical Education \&amp; Sport Pedagogy 4:162-172

120. Mitchell SA, Oslin JL, Griffin LL (2003). Sport foundations for elementary physical education: a tactical games approach. Champaign, IL: Human Kinetics

121. Mortágua L, Peñas CL (2007). A avaliação do rendimento individual em desportos de invasão na educação física. A participação dos alunos do ensino básico numa perspectiva de coavaliação. In: 1ํo Congresso Internacional de Jogos D esportivos. Faculdade de Desporto, Universidade do Porto, Porto, Portugal
122. Musch E, Mertens B, Timmers E, Mertens T, Graça A, Taborsky F, Remy C, De Clercq D, Multael M, Vonderlynck $\checkmark$ (2002). An innovative didactical invasion games model to teach basketball and handball, presented on $\mathrm{cd}$. In: 7th A nnual Congress of the European College of Sport Science. Athens. Greece

123. Nevett M, Rovegno I, Babiarz M (2001). Fourth-grade children's knowledge of cutting; passing and tactics in invasion games after a 12-lesson unit of instruction. Journal of Teaching in Physical Education 20:389-401

124. Nevett M, Rovegno I, Babiarz M, McCaughtry N (2001). Changes in basic tactics and motor skills in an invasiontype game after a 12-lesson unit of instruction. Journal of Teaching in Physical Education 20:352-369

125. Ormond TC, DeMarco GM, Smith RM, Fischer KA (1995). Comparison of the sport education and traditional approaches to teaching secondary school basketball (abstract). Research Q uarterly for Exercise \& Sport 66:A-66

126. Oslin JL (1996). Tactical approaches to teaching games. JOPERD 67:27

127. Oslin JL, Mitchell S, Griffin L (1998). The Game Performance Assessment Instrument (GPAI): Development and preliminary validation. Journal of Teaching in Physical Education 17:231-243

128. Pinto D, Graça A (2004). GPAI - um instrumento de avaliação da participação do aluno no jogo. In: Ferreira AP, Ferreira V, Peixoto C, Volossovitch A (eds) Gostar de basquetebol: Ensinar a jogar e aprender jogando. Faculdade de Motricidade Humana, Cruz Quebrada, p 81-91

129. Placek J (1983). Conceptions of success in teaching: Busy, happy and good? In: Templin TJ, Olson JK (eds) Teaching in Physical Education. Human Kinetics, Champaign, Illinois, $p$ 46-56

130. Pope CC (2005). Once more with feeling: affect and playing with the TGfU model. Physical Education and Sport Pedagogy 10:271 - 286

131. Pope CC, Grant BC (1996). Student experiences in sport education. Waikato Journal of Education 2:103-118

132. Rauschenbach J (1996). Charge and catch coop: two games for teaching game play strategy. JOPERD 67:22-24

133. Ricardo V (2005). N ovas Estratégias de Ensino para os Jogos Desportivos: U m estudo experimental na modalidade de basquetebol em alunos do 90 ano de escolaridade. In: Faculdade de Ciências do Desporto e de Educação Física, Universidade do Porto, Porto

134. Ricardo V, Graça A (2007). Novas Estratégias de Ensino do Jogo de Basquetebol: estudo experimental em alunos do 9o ano de escolaridade. In: 1ํ Congresso Internacional de Jogos D esportivos: Olhares e contextos da performance - da iniciação ao alto rendimento. Faculdade de Desporto, Universidade do Porto, Porto

135. Richard J-F (1998). La mesure et I'evaluation de la performance en jeux et sports collectifs: La participation des eleves du primaire dans une perspective d'evaluation authentique. In:Universite Laval Laval, Canada

136. Richard J-F, Godbout $P$, Tousignant $M$, Gréhaigne J-F (1999). The Try-Out of a Team Sport Performance Assessment Procedure in Elementary and Junior High School Physical Education Classes. Journal of Teaching in Physical Education 18:336-356

137. Richard JF, Godbout P, Gréhaigne J-F (2000). Students' precision and interobserver reliabiity of performance 
assessment in team sports. R esearch Q uarterly for Exercise and Sport 71:85-91

138. Richard JF, Wallian N (2005). Emphasizing student engagement in the construction of game performance. In: Griffin LL, Butler J (eds) Teaching Games for Understanding : theory, research, and practice. Human Kinetics, Champaign, IL, p 19-32

139. Rink J (1993). Teaching physical education for learning. St. Louis: Mosby

140. Rink J (1996). Tactical and Skill Approaches to Teaching Sport and Games: Introduction. Journal of Teaching in Physical Education 15:397-398

141. Roth K, Kroeger C, Memmert D (2002). Ballschule Rueckschlagspiele. Schorndorf; Germany: Hofmann

142. Rovegno I (1991). A Participant-Observation Study of Knowledge Restructuring in a Field-Based Physical Education Methods Course. Research Q uarterly for Exercise and Sport 62:205-212

143. Rovegno I (1992). Learning a new curricular approach: mechanisms of knowledge acquisition in preservice teachers. Teaching and Teacher Education 8:253-264

144. Rovegno I (1992). Learning to teach in a field-based methods course; the development of pedagogical content knowledge. Teacher and Teacher Education 8:69-82

145. Rovegno I (1993). Content Knowledge Acquisition during Undergraduate Teacher Education: Overcoming Cultural Templates and Learning through Practice. A merican Educational Research Journal 30:611-642

146. Rovegno I (1993). The development of curricular knowledge: a case of problematic pedagogical content knowledge during advanced knowledge acquisition. R esearch Q uarterly for Exercise and Sport 64:56-68

147. Rovegno I (1995). Theoretical Perspectives on Knowledge and Learning and a Student Teacher's Pedagogical Knowledge of Dividing and Sequencing Subject Matter. Journal of Teaching in Physical Education 14:284-304

148. Rovegno I (1998). The Development of In-Service Teachers' Knowledge of a Constructivist Approach to Physical Education: Teaching Beyond Activities. R esearch Q uarterly for Exercise and Sport 69:147-162

149. Rovegno I, Bandhauer D (1994). Child-designed games: experience changes teachers' conceptions. JOPERD 65:6063

150. Rovegno I, Bandhauer D (1997). Psychological Dispositions That Facilitated and Sustained the Development of Knowledge of a Constructivist Approach to Physical Education. Journal of Teaching in Physical Education 16:136-154

151. Rovegno I, Nevett M, Babiarz M (2001). Learning and teaching invasion-game tactics in 4th grade: Introduction and theoretical perspective. Journal of Teaching in Physical Education 20:341-351

152. Rovegno I, Nevett M, Brock S, Babiarz M (2001). Teaching and learning basic invasion-game tactics in 4th grade: $A$ descriptive study from situated and constraints theoretical perspectives. Journal of Teaching in Physical Education 20:370388

153. Siedentop D (1987). The theory and practice of sport education. In: G.Barrette, Feingold R, Rees C, Piéron M (eds) $M$ yths; models and methods in sport pedagogy. Human Kinetics, Champaign; IL, p 79-85

154. Siedentop D (1988). An ecological model for understand- ing teaching/learning in Physical Education. In: Proceedings of the 1988 Seoul Olympic Scientific Congress. Seoul Olympic Scientific Congress Organizing Committee, Seoul, Korea, $p$ 111-124

155. Siedentop D (1994). Sport education: Quality PE trhough positive sport experiences. Champaign, IL: Human Kinetics

156. Siedentop D (1996). Physical education and educational reform: The case of sport education. In: Silverman S, Ennis $\mathrm{C}$ (eds) Student learning in physical education. Human Kinetics, Champaign, III., p 247-267

157. Siedentop D (1998). What is sport education and how does it work? JOPERD 69:18

158. Siedentop D (2002). Sport education: A retrospective. Journal of Teaching in Physical Education 21:409-418

159. Siedentop D, Hastie P, Mars HVD (2004). Complete guide to Sport Education. Champaign IL: Human Kinetics

160. Siedentop D, Mand C, Taggart A (1986). Physical education: Teaching and curriculum strategies for grades 5-12. Palo Alto: Mayfield Publishing Company

161. Strikwerda-Brown J, Taggart A (2001). No longer voiceless and exhausted: sport education and the primary generalist teacher. ACH PER H ealthy Lifestyles Journal 48:14-17

162. Tallir I, Lenoir M, Valcke M (2004). Assessment of game play in basketball. In: Light R, Swabey K, Brooker R (eds) Proceedings of the 2 nd International Conference: Teaching Sport and Physical Education For Understanding, 11 - 14 December 2003. University of Melbourne, Melbourne, Australia, $p$ 99-107

163. Tallir I, Musch E, De Bourdheaudhuij I, Lenoir M, Mertens B (2002). Tactical Game Performance in Basketball : A coding instrument for the individual off-the-ball decisions in 3 on 3 game play. In: AIESEP Congress. A Coruña; Spain.

164. Tallir I, Musch E, Lanoo K, Van de VoordeJ (2004). Validation of video-based instruments for the assessment ofgame performance in handball and soccer. In: Light $\mathrm{R}$, Swabey K, Brooker R (eds) Proceedings of the 2 nd International Conference: Teaching Sport and Physical Education For Understanding, 11 - 14 December 2003. University of Melbourne, Melbourne, Australia, p 108-113

165. Tallir IB, Musch E, Valcke M, Enoir M (2005). Effects of Two Instructional Approaches for Basketball on Decisionmaking and Recognition Ability. Int. J. Sport Psychol. 36:107

166. Tavares F, Greco P, Garganta J (2006). Perceber, conhecer e agir nos jogos desportivos colectivos. In: Tani G, Bento JO, Petersen RS (eds) Pedagogia do desporto. Guanabara Koogan, Rio de Janeiro, p 284-298

167. Thorpe R, Bunker D (1985). Un nuovo approccio dell'insegnamento dei giochi nell'ambito del programma di educazione fisica. / A new approach to the teaching of games in the physical education curriculum. In: In, L'insegnamento dei giochi sportivi, Rome, CONI, Scuola dello Sport, 1985, p. 217-225., Italy

168. Thorpe R, Bunker D (1989). A Changing focus in games teaching. In: Almond L (ed) The place of physical education in schools. Kogan/Page, London, p 42-71

169. Thorpe R, Bunker D, Almond L (1984). A Change in focus for the teaching of games. In: Piéron M, Graham G (eds) Sport Pedagogy: Olympic Scientific Congress. Human Kinetics, Champaign; IL, p 163-169

170. Thorpe R, Bunker D, Almond L (eds) (1986). Rethinking Games Teaching. Dept. of Physical Education and Sports Science, University of Technology, Loughborough, England 
171. Tjeerdsma B, Rink J, Graham K (1996). Students Perceptions; Values; and Beliefs to; During; and After Badminton Instruction. Journal of Teaching in Physical Education 15:464-476

172. Turner A (1996). Teaching for understanding: Myth or reality? JO PERD 67:46-48/55

173. Turner A, Martinek T (1992). A comparative analysis of two models for teaching games (Technique approach and game centered (tactical focus approach). International journal of physical education (Schorndorf, FRG) 29(4), 4th Quarter 1992, 1531 Refs:35

174. Turner A, Martinek T (1999). An investigation into teaching games for understanding : effects on skill; knowledge; and game play. Research Q uarterly for Exercise and Sport 70:286-296

175. Wallhead T, O'Sullivan M (2005). Sport Education: physical education for the new millennium? Physical Education \& Sport Pedagogy 10

176. Wall lhead TL, Deglau D (2004). Effect of a Tactical Games Approach on Student Motivation in Physical Education. In: 2004 A AHPERD National Convention and Exposition. New Orleans, LA

177. Waring M, Almond L (1995). Game-centred games: a revolutionary or evolutionary alternative for games teaching. European Physical Education Review 1:55-66

178. Werner P, Thorpe R, Bunker D (1996). Teaching games for understanding: Evolution of a model. JOPERD 67:28-33 